\title{
Myocardial Reperfusion: A Double-edged Sword?
}

\author{
Eugene Braunwald and Robert A. Kloner \\ Department of Medicine, Harvard Medical School, Brigham and Women's Hospital, and Beth Israel Hospital, Boston, \\ Massachusetts 02115; and Wayne State University School of Medicine and Harper Hospital, Detroit, Michigan 48201
}

\section{Introduction}

Although Herrick, in his now classic description of acute myocardial infarction, attributed this condition to coronary thrombosis (1), many pathologists have questioned the causality of the latter (2), which led to a lively debate about this subject that raged for several decades. However, the angiographic finding by DeWood et al. (3) in 1980 of obstructive coronary thrombi in a large majority of patients studied during the first hours of acute transmural myocardial infarction, coupled with the experimental observation that myocardium can be salvaged by early reperfusion $(4,5)$, led to efforts to dissolve, mechanically compress, or surgically remove or bypass the offending thrombi. The demonstration that coronary thrombi can be lysed successfully in the majority of patients by the intracoronary injection of streptokinase (6) as well as by the technically much simpler technique of the intravenous administration of tissue plasminogen activator $(7,8)$ has raised the hope that large quantities of ischemic myocardium in the distribution of the occluded coronary artery, which are otherwise destined to become necrotic, might be salvaged by timely application of thrombolytic reperfusion. Currently, substantial efforts are underway to perfect techniques to achieve early reperfusion. Although major attention is being directed to thrombolytic therapy, reperfusion can also be achieved by percutaneous transluminal angioplasty and surgical revascularization. The relative advantages and limitations of each of these methods have been discussed elsewhere (9).

Both the duration and severity of myocardial ischemia are important determinants of cell death (10); indeed, the product of the deficit of myocardial blood flow and the duration of ischemia has been shown to correlate well with the ultimate extent of myocardial necrosis (11). Reimer and Jennings (10) demonstrated in the dog that following coronary occlusion a "wavefront" of myocardial necrosis advances progressively from the subendocardium through the myocardial wall to the subepicardium, and as the time interval between coronary occlusion and reperfusion lengthens, the salvagable tissue becomes confined to the subepicardium. In the absence of substantial collateral blood flow, necrosis of cardiac tissue occurs rapidly, e.g., in the subendocardium of the anesthetized dog, which has relatively little collateral flow; it commences about $20 \mathrm{~min}$ after after coronary occlusion and it is essentially complete in the subepicardium, which has greater collateral flow in $3 \mathrm{~h} \mathrm{(12).} \mathrm{Similar} \mathrm{con-}$ siderations apply to patients in whom the subendocardium also

Received for publication 10 July 1985.

J. Clin. Invest.

(C) The American Society for Clinical Investigation, Inc.

$0021-9738 / 85 / 11 / 1713 / 07 \quad \$ 1.00$

Volume 76, November 1985, 1713-1719 is most susceptible to ischemic damage. It is possible that salvage by reperfusion of even a subepicardial rim of tissue might exert a beneficial effect out of proportion to the actual mass of myocardium salvaged, since this rim might prevent infarct expansion, ventricular dilatation, and formation of aneurysms with resultant heart failure. For these reasons, reperfusion of ischemic myocardium carried out at the earliest possible time following coronary occlusion is viewed as an important goal.

While reperfusion, by definition, relieves or at least greatly reduces ischemia, it also results in a complex group of phenomena, some of which may initially appear to be deleterious. It is these apparently deleterious phenomena which form the subject of this essay. They include the hastening of the necrotic process of irreversibly injured myocytes, cell swelling, the no-reflow phenomenon, hemorrhagic myocardial infarction, the calcium and oxygen paradox, the production of oxygen-derived free radicals which may damage ischemic myocytes, and the prolonged postischemic depression of ventricular function or the so called "stunning" of the myocardium. Reperfusion of ischemic tissue may also induce a number of important cardiac electrophysiologic changes which in turn can cause a variety of arrhythmiassome benign, others potentially lethal (13); these are not considered here.

\section{Hastening of necrosis of irreversibly injured cells}

In 1960, Jennings et al. (14) reported both structural and electrophysiological changes associated with coronary reperfusion and first suggested that reperfusion may actually hasten the necrotic process of irreversibly injured myocytes. Although reperfusion provides the oxygen and metabolic substrates necessary for the recovery of reversibly injured myocardium, irreversibly injured myocytes subjected to coronary reperfusion develop the ultrastructural appearance of "explosive swelling," including architectural disruption, contraction bands, and intramitochondrial calcium-phosphate granules. Hence, reperfusion of myocytes already irreversibly damaged by ischemia results in an acceleration of the necrotic process. It is generally accepted that ischemia is the primary cause of irreversible injury to myocytes following coronary occlusion and that reperfusion of irreversibly injured cells hastens the necrotic process, perhaps by providing excess fluid and electrolytes to cells with damaged sarcolemma. However, whether or not reperfusion is capable of causing a population of reversibly injured cells to become irreversibly injured is not yet clear. Nearly all experimental studies have shown that early coronary reperfusion reduces the size of infarction. Several investigations have suggested that some myocytes which are reversibly injured at the time that coronary occlusion is terminated undergo irreversible cell damage during reperfusion. If this is so, then it might be expected that protective pharmacologic agents administered during the reperfusion phase should be capable of limiting tissue necrosis; indeed, this has been demon- 
strated $(15,16)$. However, in a recent study $(17)$, we found that administration of a calcium channel antagonist at the time of coronary reperfusion did not limit infarct size, a finding which does not support the suggestion that reperfusion causes necrosis of reversibly injured myocytes. Although the issue is not entirely settled, the prevailing view is that if reperfusion causes any necrosis of reversibly injured myocardium, the quantity of tissue so affected is small (18).

\section{Ischemic cell swelling}

An impairment of cell volume regulation is characteristic of ischemic tissue injury (19). Severe persistent ischemia, in the absence of reperfusion, may cause cell swelling and a net gain in tissue water; the mechanism of the latter has not been identified with certainty but it might be secondary to ischemiainduced depression of the sodium-potassium exchange pump in the sarcolemma, to the development of increased cell membrane permeability, and/or the formation of osmotically active intracellular particles (20). Regardless of the specific mechanism(s) responsible for the impairment of cell-volume regulation, the finding of a correlation between increases in myocardial water and reductions in myocardial blood flow (21) suggests that swelling of myocytes may contribute to vascular compression. In addition, ischemia-induced swelling of endothelial cells may contribute to increased vascular resistance. The hypothesis that cell swelling contributes to vascular compression is supported by the observation that perfusion of the ischemic myocardium with hypertonic mannitol prevented both accumulation of intracellular water and progressive increase in vascular resistance in the ischemic tissue. The heart is not unique in this response to ischemia; studies in the brain and kidney have suggested that ischemia-induced cell swelling may cause compression of the lumina of small vessels leading to reduced perfusion of these organs as well (22).

With coronary reperfusion there is a marked increase in cellular swelling (23). While this increase is dramatic in irreversibly injured cells, it may also be seen transiently and to a lesser extent in reversibly injured tissue $(24,25)$. This so-called "explosive" cell swelling of irreversibly injured cells (26) appears to be caused by an ischemia-induced sarcolemmal abnormality which causes a serious defect in regulation of cell volume and which is associated with marked increases in tissue water, sodium, chloride, and calcium. The hypothesis that sarcolemmal defects may contribute to "explosive" cell swelling as well as irreversible myocyte injury is supported by studies using radiolabeled anticardiac myosin $\left(\mathrm{Fab}^{\prime}\right)_{2}$ antibody fragments which have shown that loss of cell membrane integrity occurs very early during postocclusion reflow (27).

\section{The "no-reflow" phenomenon}

After release of vascular occlusion, blood flow may not return uniformly to all portions of the previously ischemic tissue; this condition has been termed the "no-reflow" phenomenon (23). The failure to restore perfusion after release of occlusion has been observed in a variety of organs, including the heart, kidney, brain, and skin. Several mechanisms have been proposed for the no-reflow phenomenon. Ultrastructural studies of zones of no-reflow show actual microvascular damage which could impede inflow into the ischemic zone (23). These microvascular abnormalities include localized zones of endothelial cell swelling, termed "blebs," which appear to plug capillaries; increased permeability of capillaries with and without gaps in the endothelium leading to rouleaux formation of erythrocytes with subsequent stasis; plugging of the microvascular bed by leukocytes (28); microscopic zones of hemorrhage (5); and myocyte swelling which can compress the adjacent microvasculature. In addition, contracture of myocytes is another possible mechanism by which "no-reflow" could occur. While it has been proposed that the no-reflow phenomenon may be caused by fibrin plugs, this is unlikely since high dose streptokinase does not abolish the noreflow phenomenon (29).

Does the no-reflow phenomenon contribute to irreversible myocardial cell injury? Studies utilizing fluorescent dye which have determined the location of zones of no-reflow in relationship to anatomic zones of irreversibly injured myocytes suggest that the no-reflow phenomenon probably does not directly contribute to myocardial cell death $(23,29)$. In these studies, the zone of no-reflow was always smaller than and contained within areas in which the myocytes were already dead (Fig. 1).

\section{Reperfusion-induced hemorrhage}

It has been observed repeatedly in experimental animals that infarcts produced by transient periods of ischemia followed by reperfusion contain areas of hemorrhage $(5,30)$. Hemorrhagic myocardium has also been found at necropsy in patients with acute myocardial infarction who underwent thrombolytic reperfusion or surgical revascularization (31). Accordingly, there has been concern that reperfusion can convert a bland infarct into a hemorrhagic one and, more importantly, that hemorrhage due to coronary reperfusion may lead to the extension of myocardial necrosis (32).

Hemorrhagic infarction is caused by reperfusion of myocardium in which the damaged microvasculature allows the extravasation of blood into the extravascular space. It is now clear that in dogs relatively short periods ( $<40 \mathrm{~min}$ ) of severe ischemia cause necrosis of myocytes but usually not of vascular endothelial cells, and reperfusion of tissue in which the endothelium has been spared of injury will not cause hemorrhagic infarction. However, long periods of severe ischemia damage not only myocytes but cause changes in the capillary endothelial cells as well (33). The latter consist of localized zones of endothelial swelling which protrude into the vessel lumen, of gaps within the endothelium, and of loss of endothelial pinocytotic vesicles. It should be emphasized that ultrastructural evidence of irreversible damage to myocytes, including disrupted sarcolemmal membranes, is usually present before such structural alterations occur in the microvasculature; that microvascular damage does not appear to be the primary cause of death of ischemic myocytes (34); and that microvascular damage is confined to the most subendocardial portion of the infarct where the myocardial cells are already irreversibly injured (Fig. 1). Reimer et al. (5) have reported that reperfusion-induced myocardial hemorrhage, as noted on gross inspection and histologic examination, was always confined to and never extended outside areas of myocardial cell necrosis. We have observed $(24,30)$ that dogs subjected to a 2 $h$ coronary occlusion followed by prolonged reperfusion usually had visible hemorrhage within the infarct, that the hemorrhage was smaller than the zone of myocardial necrosis, and that a nonhemorrhagic rim of infarcted tissue surrounded the zone of hemorrhage. Similar observations have been made in patients in whom reperfusion was carried out by thrombolysis or coronary bypass surgery (31). However, there is some evidence that alterations in vascular permeability may occur relatively soon after 


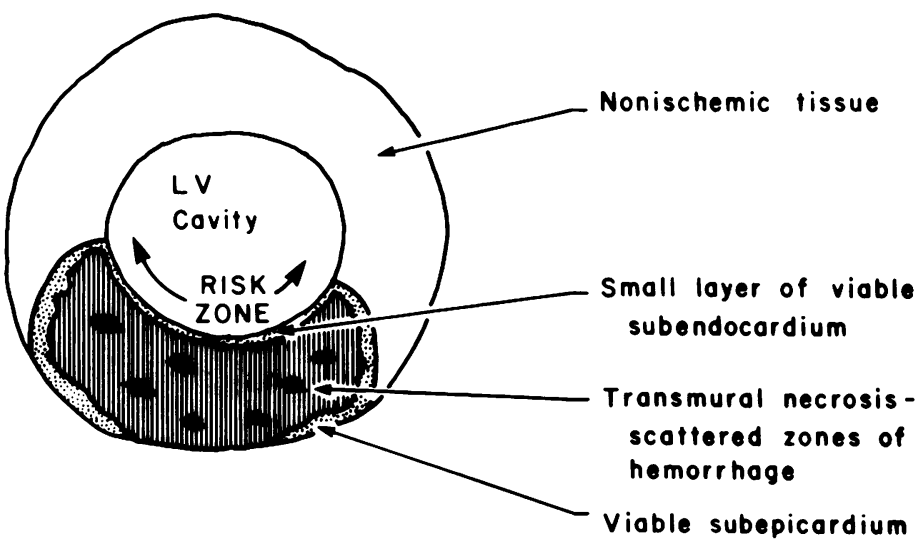

A

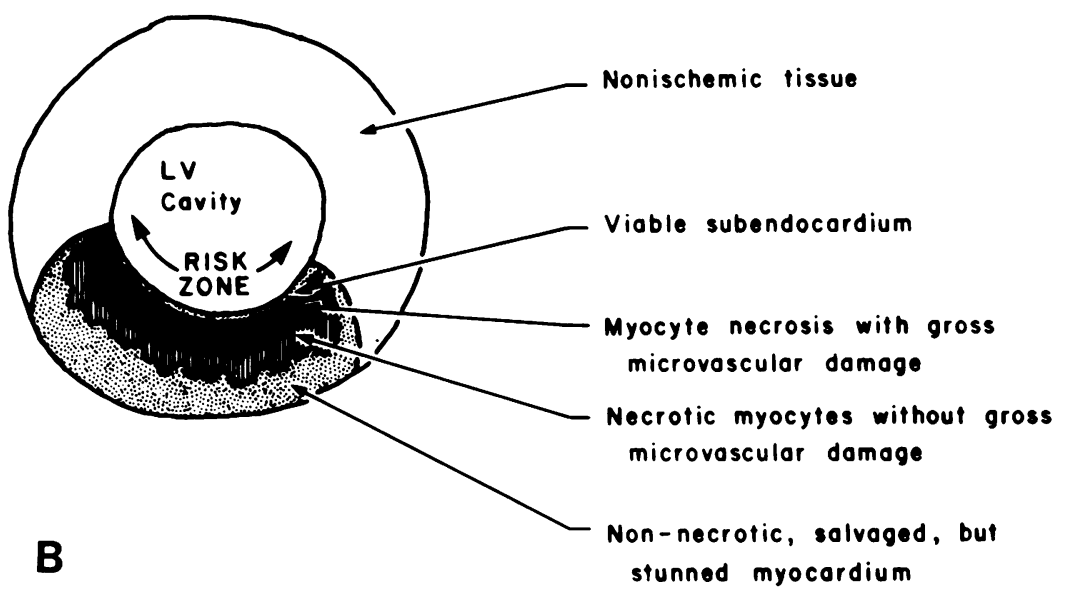

Figure 1. $(A)$ Schematic diagram showing a transverse section through a canine left ventricle subjected to a permanent coronary occlusion without reperfusion. The white area represents nonischemic myocardium supplied by the nonoccluded vessel. The infarct (hatched area) is transmural or neartransmural. There are scattered zones of hemorrhage (solid black). A small layer of viable subendocardium is present which derives its oxygen directly from the ventricular cavity. Where collateral flow is high, there may be a small rim of surviving subepicardium (stippled areas). (B) Schematic diagram showing a transverse section through a canine left ventricle subjected to coronary occlusion followed within 1 or $2 \mathrm{~h}$ by coronary reperfusion. The hatched and solid black areas represent the infarct which is confined to the inner half of the myocardium. The solid black area represents the zone of gross microvascular damage including the zones of no-reflow and hemorrhage. It is smaller than the total infarct. The remainder of the infarct without severe microvascular damage is represented by the hatched area and is located in the mid-myocardium. The epicardial portion of the ischemic zone (stippled area) has been salvaged by coronary reperfusion. It is nonnecrotic but stunned (postischemic ventricular dysfunction) for hours to days following coronary reperfusion. coronary occlusion (34), perhaps even before myocytes become irreversibly injured.

Considering the observations summarized above, it appears that prolonged ischemia causes severe microvascular damage and reperfusion hemorrhage which does not extend infarction but occurs only in areas in which the myocytes are already irreversibly damaged. In slightly less ischemic areas, the myocytes are also irreversibly damaged, but the microvasculature remains intact. Reperfusion of such areas does not salvage tissue but results instead in a bland infarct. Thus, myocardial hemorrhage appears to be a highly visible but probably relatively unimportant consequence of reperfusion insofar as infarct size is concerned, although it may alter (increase) the stiffness of the ventricle. Furthermore, reperfusion hemorrhage has been shown not to alter hydroxyproline content or thickness of healing infarct scars (35).

\section{The calcium paradox and the oxygen paradox}

Zimmerman and colleagues (36) described the calcium paradox as a condition in which the sudden readmission of calcium to the perfusate after a brief period in which hearts are perfused with calcium-free media causes massive tissue disruption, enzyme release, the development of contracture, and marked reductions of high energy phosphate stores $(37,38)$. Perfusion of hearts with calcium-free media even for brief periods leads to increased cell membrane permeability; the primary lesion in the calcium paradox may be the separation of the external lamina and surface coat of the glycocalyx, disruption of the sarcolemmal bilayer, and the loss of intracellular calcium during the period of calcium depletion (38). These changes may predispose the cell to a massive influx of calcium and loss of the regulation of cell volume during reperfusion. The influx of calcium may activate the production of free radicals, activate phospholipases which damage the sarcolemma, or disrupt mitochondria. These changes can lead to contracture, cell swelling, and necrosis.

It has been appreciated for a decade that the reintroduction of oxygen to hypoxic or anoxic myocardium may also be detrimental, leading to excess liberation of cardiac enzymes and contracture. Indeed, the effects of restoring calcium to the perfusate after a short period of calcium depletion (the calcium paradox) or of restoring oxygen after a relatively long period of anoxia or ischemia (the oxygen paradox) resemble each other in many ways (37-39). In both conditions, the sarcolemma is damaged, intracellular vesicles develop, and mitochondria move to the cell border. While ultrastructural changes in myofibrils and sarcoplasmic reticulum are observed in the rat heart after 105 min of anoxia, far more striking morphologic changes occur after $5 \mathrm{~min}$ of reoxygenation following this period of anoxia (40). Interestingly, Hearse et al. (37) found that reperfusion of ischemic hearts with anoxic fluid resulted in no increase in dam- 
age and no significant increase in enzyme leakage. However, reoxygenation of the anoxic perfused rat heart causes an immediate and massive enzyme release, and sudden and major ultrastructural damage, both of which are directly attributable to the resumption of oxidative metabolism.

In the calcium paradox, there is passive movement of calcium into the cytoplasm, explosive cell swelling, and calcium-induced myofibrillar contracture. In the oxygen paradox, it is likely that the oxygen-induced reenergization of the electron transport chain triggers the uncontrolled uptake of calcium by the mitochondria from the cytoplasm. Reperfusion or reoxygenation of ischemic myocardium causes contracture of myofibrils, disruption of the sarcolemma, and the appearance of intramitochondrial calcium phosphate particles. The uptake of calcium by myocytes during reperfusion probably occurs as a consequence of passive diffusion into the cytoplasm. Interestingly, reduction of calcium concentration in the reperfusate influences mechanical recovery favorably (41).

Since ischemic myocardium is not exposed to a calciumfree environment (except when cardioplegia is induced with a calcium-free solution), the calcium paradox is probably not involved in ischemia and clinical reperfusion. However, events observed in the similar and probably closely related oxygen paradox suggest that restoration of aerobic metabolism may be a critical component of reperfusion-mediated events and might extend the severity of ischemic damage and limit the value of reperfusion.

\section{Oxygen-derived free radicals}

Considerable attention is now being devoted to the mechanism responsible for the oxygen paradox. A leading contender is the production of oxygen-derived free radicals, such as the superoxide anion $\left(\mathrm{O}_{2}^{-}\right)$, the hydroxyl radical $(\cdot \mathrm{OH})$, and $\mathrm{H}_{2} \mathrm{O}_{2}$, which occurs as a consequence of the reintroduction of molecular oxygen into previously ischemic tissue during reperfusion (42). These substances are chemically reactive because they contain an open bond as a consequence of an odd number of electrons and they appear to be responsible, at least in part, for the tissue damage consequent to reperfusion (43).

Studies in a variety of tissues, including the central nervous system (44), the intestine (45), and the myocardium (46) suggest that oxygen-derived free radicals do contribute importantly to ischemic injury. Severe swelling and lysis of mitochondria in cardiac myocytes and vascular endothelial cells have been demonstrated when isolated cardiac tissue was exposed to solutions capable of generating free radicals $(38,40,43)$. Oxygen-derived free radicals cause cellular damage by reacting with polyunsaturated fatty acids and result in the formation of lipid peroxides and hydroperoxides (47), which in turn inhibit many membranebound enzymes, initiate chain-propagating reactions capable of damaging the sarcolemma, and thereby cause the disruption of cellular integrity (48). These radicals also disrupt mitchondrial membranes and the resultant mitochondrial damage may also interfere with the production of ATP, thereby contributing further to ischemic damage of the myocardium (42). In addition to damaging the sarcolemma and mitochondria, oxygen-derived free radicals may also impair calcium transport by sarcoplasmic reticulum (49).

Several mechanisms appear to be responsible for the formation of oxygen-derived free radicals during reperfusion. During ischemia, ATP is broken down to AMP which is ultimately metabolized to hypoxanthine. The above mentioned elevation of cytosolic calcium concentration caused by ischemia enhances the conversion of xanthine dehydrogenase to xanthine oxidase $(42,50)$. According to this concept, when molecular oxygen is reintroduced to cells containing high concentrations of hypoxanthine, this enzyme causes the release of $\mathrm{O}_{2}^{-}$and $\mathrm{H}_{2} \mathrm{O}_{2}$. Secondly, during myocardial ischemia, there is loss of the enzymes, superoxide dismutase, catalase, and glutathione peroxidase (47, 51 ), which could protect the heart from oxygen-derived free radicals. The autoxidation of catecholamines could provide another source of free radicals $(52,53)$.

Oxygen-derived free radicals are also derived from leukocytes, where they participate in the destruction of bacteria and act as mediators of inflammatory responses (54) and of cytotoxicity in experimentally produced inflammation (55). Activated human neutrophils depress both the uptake of $\mathrm{Ca}^{++}$by myocytes and the activity of $\mathrm{Ca}^{++}$-stimulated, $\mathrm{Mg}^{++}$-dependent ATPase, which are actions that can be prevented by the combination of superoxide dismutase and catalase, and which therefore are presumably caused by oxygen-derived free radicals (56). Endoperoxide intermediates, resulting from the conversion of arachidonic acid, also lead to the production of oxygen-free radicals by leukocytes and other cell types in the heart (57). Leukocytes that are activated during inflammation release a variety of other cytotoxic products, including lysosomal hydrolases, neutral proteases, and arachidonic acid which is converted by lipoxygenases to eicosatetranoic acids and leukotrienes; the latter cause coronary vasoconstriction and increase vascular permeability (58).

Leukocytes begin to migrate into ischemic myocardium from adjacent tissue during the first few hours following coronary occlusion (59). Of course, they enter ischemic tissue in much greater quantities during reperfusion, particularly when the vascular endothelium has been injured. A role for leukocytes in causing myocardial necrosis has been suggested by Romson et al. (60), who observed that leukocyte depletion by the administration of neutrophil antiserum was associated with a significant reduction in infarct size in the dog subjected to coronary occlusion.

\section{Possible role of free radical scavengers}

The hypothesis that oxygen-derived free radicals play a significant role in the tissue damage observed following ischemia and reperfusion is based not only on the finding that substantial injury occurs when molecular oxygen is reintroduced into ischemic tissue but also on the observation that this injury can be prevented by enzymes that "scavenge" the superoxide radical by catalyzing its dismutation to hydrogen peroxide and oxygen. For example, Shlafer et al. $(61,62)$ reported that the addition of superoxide dismutase and catalase to the perfusion fluid enhances recovery of left ventricular function and reduces ischemiainduced elevation of coronary vascular resistance in isolated perfused hearts. The combination of dismutase and catalase has also been reported to protect perfused rabbit hearts after $3.5 \mathrm{~h}$ of hypothermic ischemia and the combination of dismutase and mannitol improves recovery of left ventricular function following hypothermic hyperkalemic cardioplegia (63) before reperfusion. The demonstration by Jolly et al. (46) that the administration of superoxide dismutase and catalase to dogs with coronary occlusion prior to the onset of reperfusion reduces infarct size, while the failure of these substances to do so when they are 
administered following the onset of reperfusion, supports the suggestion that reperfusion damage occurs when the previously ischemic heart is reexposed to oxygen.

Other free radical scavengers also appear to protect the heart from reperfusion injury. Thus, Lefer et al. (64) found in the reperfused cat heart that the iodosphenol, MK-447, when administered in combination with a cyclooxygenase inhibitor, restored ventricular performance, reduced myocardial edema, and prevented leakage of myocardial creatine kinase activity. Alpha tocopherol, by providing hydrogen atoms, may also exert a protective effect by neutralizing oxygen-derived free radicals (54). Free radical scavengers exert a beneficial action in organs other than the heart as well. Thus, MK-477 was found to prolong the survival of cats subjected to traumatic shock (64), and the administration of superoxide dismutase to cats with ischemia of the ileum has been shown to protect this tissue from ischemic injury (45).

\section{Response to reperfusion: the "stunned" myocardium}

The initial mechanical response to abrupt coronary artery occlusion is a conversion of active shortening of the ischemic myocardium into passive systolic lengthening, i.e., paradoxical systolic expansion. The time, rate, and extent of recovery of systolic contraction of ischemic segments is a function of the duration of the occlusion; with a brief ( $1 \mathrm{~min}$ ) coronary occlusion, some degree of active shortening begins to return within $20 \mathrm{~s}$ following the onset of reperfusion and the return of contractile activity is essentially complete in $30 \mathrm{~min}$. After $5 \mathrm{~min}$ of coronary occlusion, contraction of the previously ischemic myocardium remains significantly depressed for as long as $\mathbf{3 0} \mathrm{min}$ after the onset of reperfusion, and following $15 \mathrm{~min}$ of ischemia, the previously ischemic tissue continues to exhibit persistent paradoxical systolic bulging of the reperfused zone after a full hour of reflow. When a more prolonged ( 2 or $3 \mathrm{~h}$ ) occlusion is followed by reperfusion, some deterioration of cardiac function occurs immediately. However, function does return over days to weeks to that myocardium which has been salvaged by the reperfusion $(30,65)$.

In addition to the prolonged postischemic left ventricular dysfunction outlined above, biochemical abnormalities persist following reperfusion $(66,67)$. After 15 min of coronary occlusion, myocardial ATP concentration decreases substantially; it remains significantly depressed for many hours to days of reperfusion and usually returns to normal by $7 \mathrm{~d}(25,66,67)$. In other studies, creatine phosphate was shown also to fall markedly within minutes following coronary occlusion but to return to normal quite rapidly during coronary reperfusion.

Viable cardiac tissue, whose recovery of function and ATP concentration following reperfusion is delayed, has been termed "stunned" myocardium (68). Stated in another manner, stunned myocardium exhibits prolonged postischemic depression of function and high energy phosphate stores, but ultimately does recover both physiologically and biochemically. The concept of myocardial stunning may be of clinical importance in at least two ways. First, it prevents misinterpretation of the finding of the failure of early recovery of contraction of successfully reperfused ischemic myocardium (69); 1-2 wk should be allowed to elapse following reperfusion to assess the adequacy of functional recovery. Second, it explains why patients with evolving myocardial infarcts who exhibit ventricular pump failure may not exhibit improvement of ventricular function shortly follow- ing reperfusion but may require prolonged pharmacologic and/ or mechanical support of the left ventricle while myocardial function recovers gradually. The contraction of stunned myocardium can be stimulated by positive inotropic agents such as dopamine (70); the prolonged administration of this sympathomimetic agent does not appear to cause necrosis of the salvaged tissue (71).

\section{Future directions}

Myocardial reperfusion may be viewed as a double-edged sword. Although it clearly exerts deleterious effects on severely ischemic, perhaps irreversibly injured cells and may cause serious cardiac arrhythmias, when myocardial reperfusion is carried out relatively early in the course of ischemia, its net effects are usually beneficial. It is intriguing to consider that myocardial salvage may be optimized if the conditions under which reflow occurs can be modified, such as by enrichment of the reperfusion medium with substrate and/or reduction of its calcium concentration (41). Treatment with beta-adrenergic blocking agents (72) or calcium channel antagonists (17) before, at the time of, or shortly after the onset of coronary occlusion can increase substantially the quantity of ischemic myocardium that can be salvaged by reperfusion. These agents, which appear to act by delaying cell death, may leave a larger quantity of viable cells which can then be rescued by timely reperfusion. This principle might be applied clinically by administering these drugs prophylactically to patients with unstable angina pectoris or prior myocardial infarction who are at high risk of coronary occlusion (or reocclusion). However, a serious limitation of this approach is that, in order to effect substantial myocardial salvage, beta-adrenergic blockers and calcium antagonists probably must be administered before or immediately after the onset of coronary occlusion.

Interventions that enhance myocardial salvage when they are delivered at the time of reperfusion could have the enormous practical advantage of not requiring chronic prophylactic therapy of many patients, since only a few of them will ultimately develop coronary occlusion. Thus, the finding that the administration of hypertonic mannitol (15) and of fluorocarbons (73) during reperfusion augment myocardial salvage is of great interest because potentially these agents could be infused directly into the infarct-related coronary artery when the latter is opened by the intracoronary administration of a thrombolytic agent or by means of transluminal angioplasty. The demonstration, in experimental animals, that the deleterious effects of reperfusion are related importantly to the action of oxygen-derived free radicals and that these effects can be reduced or even prevented with scavengers of free radicals is intriguing. If these agents were administered systemically just before or even simultaneously with a thrombolytic agent they might augment greatly the potential benefit of reperfusion. However, the value and potential hazard of these agents in patients remains to be tested.

It is not too far fetched to consider that in the not too distant future the optimal approach to the limitation of infarct size might consist of a regimen having several components including (a) prophylactic chronic treatment of patients at high risk of coronary occlusion with a beta-adrenergic blocking agent or a calcium antagonist to slow cell death in the event coronary occlusion occurs, and $(b)$ intravenous administration of a potent, relatively fibrin-specific thrombolytic agent, such as tissue plasminogen activator, to reperfuse the severely ischemic myocardium $(7,8)$. Since myocardial necrosis proceeds rapidly after coronary oc- 
clusion, immediate therapy in the emergency room, the ambulance, or even the home may be required; thus, the regimen should also include $(c)$ the simultaneous administration of thrombolytic agents with drugs, such as free radical scavengers and/or agents which reduce leukocytic activation or infiltration, that minimize the potentially deleterious effects of reperfusion, and $(d)$ early follow-up coronary arteriography, and if severe obstruction persists in the successfully reperfused infarct-related coronary artery, the performance of percutaneous transluminal angioplasty to enhance reperfusion (9), followed by treatment with platelet anti-aggregating agents to prevent rethrombosis and with beta blockers to reduce the risk of reinfarction. In such a therapeutic strategy, myocardial reperfusion is, of course, the centerpiece, but its efficacy might be greatly enhanced by additional therapeutic measures. Given the enormous potential clinical importance of early reperfusion in limiting infarct size, preserving left ventricular function, and thus insuring patient survival, the development of simple, effective, and safe interventions to induce myocardial reperfusion and an increased appreciation of the potential benefits and limitations of reperfusion remain fertile areas for clinical investigation.

\section{References}

1. Herrick, J. B. 1912. J. Am. Med. Assoc. 59:2015-2020.

2. Ehrlich, J. C., and Y. Shinohara. 1964. Arch. Pathol. 78:432-445.

3. DeWood, M. A., J. Spores, M. D. Notske, L. T. Mouser, R. Burroughs, M. S. Golden, and H. T. Lang. 1980. N. Engl. J. Med. 303:897902.

4. Ginks, W. R., P. R. Sybers, P. R. Maroko, J. W. Covell, S. E. Sobel, and J. Ross, Jr. 1972. J. Clin. Invest. 51:2717-2723.

5. Reimer, K. A., J. E. Lowe, M. M. Rasmussen, and R. B. Jennings. 1977. Circulation. 56:786-793.

6. Laffel, G. L., and E. Braunwald. 1984. N. Engl. J. Med. 311:710717, 770-776.

7. Collen, D., E. J. Topol, A. J. Tiefenbrunn, H. K. Gold, M. L. Weisfeldt, B. E. Sobel, R. C. Leinbach, J. A. Brinker, P. A. Ludbrook, I. Yasuda, B. H. Bulkley, A. K. Robison, A. M. Hutter, Jr., W. R. Bell, J. J. Spadaro, Jr., B. A. Khaw, and E. B. Grossbard. 1984. Circulation. 70:1012-1017.

8. The Thrombolysis in Myocardial Infarction Study Group. 1985. N. Engl. J. Med. 312:932-936.

9. Braunwald, E. 1985. Circulation. 71:1087-1092.

10. Reimer, K. A., and R. B. Jennings. 1979. Lab. Invest. 40:633644.

11. DeBoer, L. W. V., R. E. Rude, R. A. Kloner, J. S. Ingwall, P. R. Maroko, M. A. Davis, and E. Braunwald. 1983. Proc. Natl. Acad. Sci. USA. 80:5784-5788.

12. Jennings, R. B., and K. A. Reimer. 1983. Circulation. 68(Suppl. I):I-25-I-36.

13. Manning, A. S., and D. J. Hearse. 1984. J. Mol. Cell. Cardiol. 16:497-518.

14. Jennings, R. B., H. M. Sommers, G. A. Smyth, H. A. Flack, and H. Linn. 1960. Pathology. 70:68-78.

15. Powell, W. J., Jr., D. R. DiBona, J. Flores, and A. Leaf. 1976. Circulation. 54:603-615.

16. Reynolds, R. D., W. E. Burmeister, R. J. Gorczynski, D. D. Dickerson, M. P. Mathews, and R. J. Lee. 1981. Cardiovas. Res. 15: 411-420.

17. Loh, H. J. M., R. A. Kloner, and E. Braunwald. 1985. Am. J. Cardiol. In press.

18. Hearse, D. J. 1984. Clin. Res. Rev. 4:58-61.

19. MacKnight, A. D. C., and A. Leaf. 1977. Physiol. Rev. 51:510572.
20. Tranum-Jensen, J., M. J. Janse, J. W. T. Fiolet, W. J. G. Krieger, C. N. D'Alnoncourt, and D. Durrer. 1981. Circ. Res. 49:364-381.

21. Powers, E. R., D. R. DiBona, and W. J. Powell, Jr. 1984. Am. J. Physiol. 247:H467-H477.

22. Chiang, J., M. Kowada, A. Ames III, R. L. Wright, and G. Majno. 1968. Am. J. Pathol. 52:455-476.

23. Kloner, R. A., C. E. Ganote, and R. B. Jennings. 1974. J. Clin. Invest. 54:1496-1508.

24. Kloner, R. A., S. G. Ellis, N. V. Carlson, and E. Braunwald. 1983. Cardiology. 70:233-246.

25. Jennings, R. B., J. Schaper, M. L. Hill, C. Steenbergen, Jr., and K. A. Reimer. 1985. Circulation Res. 56:262-278.

26. Jennings, R. B., and K. A. Reimer. 1981. Am. J. Pathol. 102: 241-255.

27. Frame, L. H., J. A. Lopez, B. A. Khaw, J. T. Fallon, E. Haber, and W. J. Powell, Jr. 1983. J. Clin. Invest. 72:535-544.

28. Engler, R. L., G. W. Schmid-Schonheim, and R. S. Pavelee. 1983. Am. J. Pathol. 111:98-111.

29. Kloner, R. A., and K. J. Alker. 1984. Circulation. 70:513-521.

30. Kloner, R. A., S. G. Ellis, R. Lange, and E. Braunwald. 1983. Circulation. 68(Suppl. I):I-8-I-15.

31. Kao, K.-J., D. B. Hackel, and Y. Kong. 1984. Arch. Pathol. Lab. Med. 108:121-124.

32. Bresnahan, G. F., R. Roberts, W. E. Shell, J. Ross, Jr., and B. E. Sobel. 1974. Am. J. Cardiol. 32:82-86.

33. Kloner, R. A., R. E. Rude, N. Carlson, P. R. Maroko, L. W. V. DeBoer, and E. Braunwald. 1980. Circulation. 62:945-952.

34. Tillmans, H., and W. Kubler. 1984. In Therapeutic Approaches to Myocardial Infarct Size Limitations. D. J. Hearse and D. M. Yellon, editors. Raven Press, New York. 107-124.

35. Roberts, C. S., F. J. Schoen, and R. A. Kloner. 1983. Am. J. Cardiol. 52:610-614.

36. Zimmerman, A. N. E., W. Daems, W. C. Hulsmann, J. Synder,

E. Wisse, and D. Durrer. 1967. Cardiovascular Res. 1:201-209.

37. Hearse, D. J. 1977. J. Mol. Cell. Cardiol. 9:605-615.

38. Hearse, D. J., S. T. Humphrey, and G. R. Bullock. 1976. J. Mol. Cell. Cardiol. 10:641-668.

39. Hess, M. L., and N. H. Manson. 1984. J. Mol. Cell. Cardiol. 16: 969-985.

40. Feuvray, D., and J. deLeiris. 1975. J. Mol. Cell. Cardiol. 7:207214.

41. Shine, K. I., and A. M. Douglas. 1983. J. Mol. Cell. Cardiol. 15: 251-260.

42. McCord, J. M. 1985. N. Engl. J. Med. 312:159-163.

43. Gauduel, Y., and M. A. Duvelleroy. 1984. J. Mol. Cell. Cardiol. $16: 459-470$

44. Demopoulous, H. B., E. S. Flamm, D. D. Pietronegro, and M. L. Seligman. 1980. Acta Physiol. Scand. 492:91-119.

45. Granger, D. N., G. Rutill, and J. McCord. 1981. Gastroenterology. 81:22-29.

46. Jolly, S. R., W. J. Kane, M. B. Bailie, G. D. Abrams, and B. R. Lucchesi. 1984. Circulation Res. 54:277-285.

47. Rao, P. S., and H. S. Mueller. 1981. Clin. Chem. 27:1027 (Abstr.). 48. Fridovich I. 1978. Science (Wash. DC). 201:875-880.

49. Hess, M. L., E. Okabe, and H. A. Kontos. 1981. J. Mol. Cell. Cardiol. 13:767-771.

50. Chambers, D. E., D. A. Parks, and E. Patterson. 1985. J. Mol. Cell. Cardiol. 17:145-152.

51. Meerson, F. Z., V. E. Kagan, Y. P. Koxlov, L. M. Belkina, and Y. V. Arkkhipenko. 1982. Basic Res. Cardiol. 77:465-485.

52. Burton, K. P., J. M. McCord, and G. Ghai. 1984. Am. J. Physiol. 246:H776-H783.

53. Singal, P. K., N. Kapur, K. S. Dhillon, R. E. Beamish, and N. S. Dhalla. 1982. Can. J. Physiol. Pharmacol. 60:1390-1397.

54. Del Maestro, R. F. 1980. Acta Physiol. Scand. Suppl. 492:153168. 
55. Fantone, J. C., and P. A. Ward. 1982. Am. J. Pathol. 107:397418.

56. Rowe, G. T., N. H. Manson, M. Caplan, and M. L. Hess. 1983. Circ. Res. 53:584-591.

57. Kuehl, F. A., J. L. Humes, M. L. Torchiana, E. A. Ham, and R. W. Egan. 1979. Adv. Inflammation Res. 1:419-430.

58. Lucchesi, B. R., J. L. Romson, and S. R. Jolly. 1984. In Therapeutic Approaches to Myocardial Infarct Size Limitation. D. J. Hearse and D. M. Yellon, editors. Raven Press, New York. 219-248.

59. Sommers, H. M., and R. B. Jennings. 1964. Lab. Invest. 13: 1491-1503.

60. Romson, J. L., B. G. Hook, S. L. Kunkel, G. D. Abrams, M. A. Schork, and B. R. Lucchesi. 1983. Circulation. 67:1016-1023.

61. Shlafer, M., P. F. Kane, and M. M. Kirsh. 1982. J. Thorac. Cardiovasc. Surg. 83:830-839.

62. Shlafer, M., P. F. Kane, V. Y. Wiggins, and M. M. Kirsh. 1982. Circulation. 66(Suppl. I):I-85-I-92.

63. Stewart, J. R., W. H. Blackwell, S. L. Crute, V. Loughlin, M. L. Hess, and L. J. Greenfield. 1982. Surg. Forum. 33:317-320.

64. Lefer, A. M., H. Araki, and S. Okamatsu. 1981. Circ. Shock. 8: 273-282.
65. Ellis, S. G., C. I. Henschke, T. Sandor, J. Wynne, E. Braunwald, and R. A. Kloner. 1983. J. Am. Coll. Cardiol. 1:1047-1055.

66. DeBoer, L. W. V., J. S. Ingwall, R. A. Kloner, and E. Braunwald. 1980. Proc. Natl. Acad. Sci. USA. 77:5471-5475.

67. Reimer, K. A., M. L. Hill, and R. B. Jennings. 1981. J. Mol. Cell. Cardiol. 13:229-239.

68. Braunwald, E., and R. A. Kloner. 1982. Circulation. 66:11461149.

69. Stack, R. S., H. R. Phillips III, D. S. Grierson, V. S. Behar, Y. Kong, R. H. Peter, J. L. Swain, and J. C. Greenfield, Jr. 1983. J. Clin. Invest. 72:84-95.

70. Ellis, S. G., J. Wynne, E. Braunwald, C. I. Henschke, T. Sandor, and R. A. Kloner. 1984. Am. Heart J. 107:13-19.

71. Arnold, J. M. O., R. A. Kloner, T. Sandor, and E. Braunwald. 1985. J. Am. Coll. Cardiol. 5:509 (Abstr.).

72. Hammerman, H., R. A. Kloner, L. L. Briggs, and E. Braunwald. 1984. J. Am. Coll. Cardiol. 3:1438-1443.

73. Forman, M. B., S. Bingham, H. A. Kopelman, C. Wehr, M. P. Sandler, F. Kolodgie, W. K. Vaugh, G. C. Friesinger, and R. Virmani. 1985. Circulation. 71:1060-1068. 